\title{
The Pathogenesis of Autosomal Dominant Polycystic Kidney Disease
}

\author{
Michael Sutters \\ Division of Renal Medicine, Johns Hopkins Bayview Medical Center, Baltimore, Md., USA
}

\section{Key Words}

Polycystin $1 \cdot$ Polycystin $2 \cdot$ Autosomal dominant

polycystic kidney disease $\cdot$ Cell calcium $\cdot$ Cell

differentiation

\begin{abstract}
In individuals with autosomal dominant polycystic kidney disease (ADPKD), renal function deteriorates as the kidneys become replaced by multitudes of fluid-filled cysts. Although the PKD genes were identified a decade ago, the pathway(s) leading from mutation to disease remain the subject of intense investigation. As a result of this work, it has become apparent that the polycystins are multifunctional proteins that, in the broadest sense, appear to be involved in the transduction of a number of environmental cues into appropriate cellular responses. It is likely that the central pathogenetic pathway for cystogenesis stems from de-differentiation of tubular epithelial cells. Available evidence indicates that loss of polycystin activity leads to subtle derangements of cell calcium regulation through several possible pathways. Abnormal cell calcium homeostasis might then lead to altered differentiation in affected cells. The study of the polycystins has revealed some entirely novel insights into fundamental cell biology but these have not yet been satisfactorily integrated into a verified pathogenetic pathway for the development of ADPKD.
\end{abstract}

Copyright (C 2006 S. Karger AG, Basel

\section{Introduction}

Autosomal dominant polycystic kidney disease (ADPKD) arises as a consequence of mutations in either one of two genes, named PKD1 and PKD2 [1, 2], which encode polycystins 1 and 2 ( $\mathrm{pc}-1$ and $\mathrm{pc}-2$ ). The existence of a third locus for ADPKD has been suggested in ADPKD families lacking PKD1 or PKD2 linkage, but because of the relatively high prevalence of PKD mutations, this situation may arise from bilineal inheritance [3]. ADPKD arising from mutations in PKD1 (ADPKD type 1) has an identical phenotype to the disease related to mutations in the PKD2 gene (ADPKD type 2), with one notable exception - ADPKD type 1 patients exhibit more rapid progression of renal disease. The fact that the phenotype is so similar in both types of ADPKD suggests that the two polycystins almost certainly function in the same diseaserelated pathway(s). However, it appears that the polycystins might also function independently of each other, and, as such, are probably active in pathways that are not directly linked to ADPKD pathogenesis. In an attempt to focus on the molecular pathogenesis of ADPKD, this review will therefore concentrate on data from studies indicating that the activity of one polycystin requires interactions with the other. Because of this focus and the constraints of space, the literature review is selective. Therefore it is with regret that many other studies of undoubted relevance to the overall cell biology of the polycystins have been omitted from the bibliography.

\section{KARGER}

(c) 2006 S. Karger AG, Basel

Fax +41613061234

E-Mail karger@karger.ch

www.karger.com

\section{Michael Sutters}

Division of Renal Medicine, Room B2N

Johns Hopkins Bayview Medical Center

4940 Eastern Avenue, Baltimore MD 21224 (USA)

Tel. +1 410550 2820, Fax +1 410550 7950, E-Mail msutters@jhmi.edu 
Fig. 1. pc-1 and pc-2 are both transmembrane proteins that interact to form a functional complex whose disturbance results in ADPKD. The $\mathrm{NH}_{2}$ terminus of pc-1 lies outside the cell and has a number of domains that are likely to bind extracellular proteins or carbohydrates. The extracellular domain of pc-1 is physiologically cleaved at the G-protein proteolytic site. The polycystin/lipoxygenase/ $\alpha$-toxin (plat) domain in the first cytoplasmic loop indicates the potential for protein-protein or membrane interactions. The shorter $\mathrm{COOH}$ cytoplasmic tail of pc- 1 contains a heterotrimeric G-protein binding and activation domain and a coiled-coil motif that is required for interaction with $\mathrm{pc}-2$. Both the $\mathrm{NH}_{2}$ and $\mathrm{COOH}$ termini of pc-2 are intracytoplasmic. The transmembrane spans of pc-2 share homology with voltage-activated $\alpha_{1}$ channels that conduct $\mathrm{Na}^{+}$and $\mathrm{Ca}^{2+}$ ions, and indicate that pc-2 might homodimerize to constitute a cation channel. The EF hand (configuration of $\mathrm{E}$ and $\mathrm{F}$ helices) is a $\mathrm{Ca}^{2+}$ sensing domain also found in $\alpha_{1}$ channels.

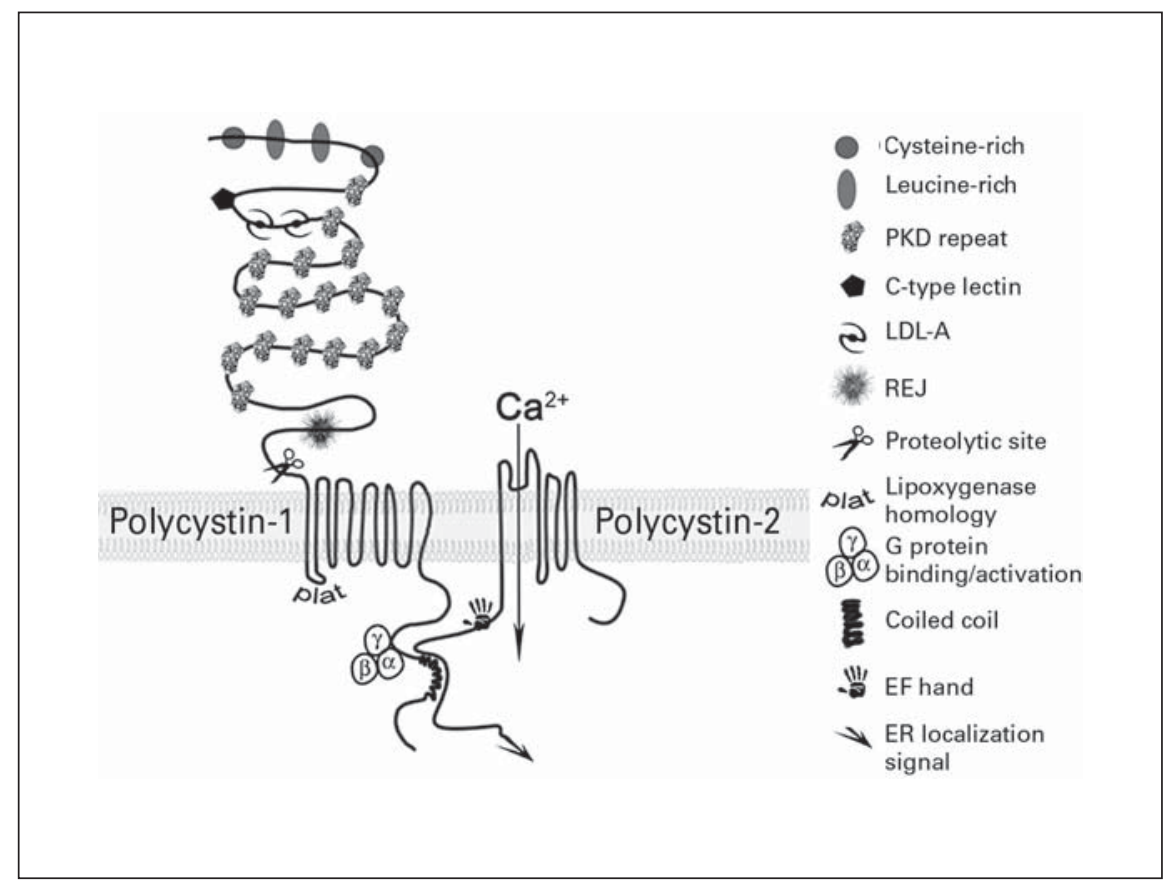

\section{The Polycystin Proteins (fig. 1)}

\section{Polycystin-1}

Polycystin-1 (pc-1) is a 4302 amino acid protein with a large extracellular $\mathrm{NH}_{2}$ terminal domain, 11 transmembrane domains and a shorter cytoplasmic $\mathrm{COOH}$ terminus. At the time of its identification, pc- 1 appeared to be an entirely new type of protein, exhibiting no overall homology with any other known protein. However, within the next 2 years the receptor for egg jelly (REJ) protein was identified in the sea urchin sperm head and noted to possess a 700 residue module which resembled a portion of the pc-1 extracellular domain [4]. This part of pc-1 was subsequently named the REJ domain. In the sea urchin, the REJ protein is required for the triggering of transmembrane cation fluxes that activate the acrosome reaction in fertilization of the sea urchin egg. As depicted in figure 1, the extracellular $\mathrm{NH}_{2}$ domain of pc-1 contains motifs likely to function as protein and carbohydrate binding sites and the PKD repeats may mediate homodimerization of pc- 1 . Between the REJ domain and the plasma membrane, there is a G-protein-coupled receptor proteolytic site (GPS). Physiologically important cleavage at this site explains why a majority of pc-1 exists as $\mathrm{COOH}$ and $\mathrm{NH}_{2}$ terminal fragments [5], the former tethering the latter to the plasma membrane. The lipoxygenase homology (polycystin/lipoxygenase/ $\alpha$-toxin or PLAT) domain in the first cytoplasmic loop of pc-1 suggests that this site subtends interactions with other proteins or the cell membrane. Together, the REJ, GPS and PLAT domains are considered the defining features of an expanding family of pc-1-like proteins. The cytoplasmic $\mathrm{COOH}$ terminus contains a $\mathrm{G}$ protein binding and activation domain [6], several phosphorylation sites and a coiled-coil domain that is required for interaction with the $\mathrm{COOH}$ terminal of polycystin-2 [7].

\section{Polycystin-2}

Polycystin-2 (pc-2) is a 968 amino acid protein whose $\mathrm{NH}_{2}$ and $\mathrm{COOH}$ termini are both cytoplasmic. This protein has six transmembrane domains (TMD) with homology to voltage-gated $\mathrm{Ca}^{2+}$ and $\mathrm{Na}^{+}$channels. TMD 5 and 6 share homology with TRP (transient receptor potential) type channels. TRP channels might mediate the so-called capacitative calcium entry required for repletion of cellular calcium stores following a calcium release response. Other TRP-type proteins serve as plasma membrane mechano-, chemo- and thermoreceptors [8]. The TMD 1-6 of pc-2 have a moderate degree of homology to the last $6 \mathrm{TMD}$ of pc-1. The $\mathrm{COOH}$ terminus of $\mathrm{pc}-2$ has a coiled coil, an ER localization signal, a calciumsensing region called an EF hand and four phosphorylation sites. Functional studies have demonstrated that pc-2 is a non-selective cation channel which transmits 
calcium [9]. Importantly, one of the proven disease-causing mutations of pc-2 results in a single amino acid substitution in the pore-forming domain that abolishes its channel function whilst preserving interaction with pc-1 and normal subcellular localization [10]. This indicates that loss of the channel function of pc-2 might be sufficient to cause ADPKD.

\section{Subcellular Localization}

Polycystin-1 has been localized to the plasma membrane of renal epithelial cells in a basal distribution in relation to cell-cell contacts such as adherens junctions, areas of cell-matrix contact and also in the central apical cilia. There is some debate about the localization of pc-2. It appears that the majority of native pc- 2 resides in the ER membrane, but significant signal is also seen to colocalize with pc-1 in the apical cilium of renal epithelial cells [11] and, as discussed below, there is some evidence that $\mathrm{pc}-2$ can function as a channel in the plasma membrane [12]. Polycystin-2 is also localized to the basal body at the base of the cilia [13]. Since this structure is derived from the centriole, it may be that $\mathrm{pc}-2$ is involved in the movement of chromosomes in mitosis. The localization of pc-1 might be dynamically regulated by pc-2 [14], and the distribution of pc-2 might be determined by trafficking proteins that shuttle pc- 2 between the ER, Golgi and plasma membranes [15]. In view of the range of locations of pc-1 and pc-2, it may be that the distribution of these proteins is dependent upon cell type or culture conditions.

\section{Molecular Genetics}

\section{The Second-Hit Hypothesis}

From an analysis of human mutations and knockout (KO) mice, it is reasonably certain that ADPKD is caused by loss of function of one or other of the polycystins. However, although one would expect a generalized abnormality (in view of the ubiquitous germline mutation affecting one PKD allele), cysts appear to arise focally in otherwise normal appearing tubule segments. Furthermore, the type of dramatic cystic degeneration seen in human disease is only evident in mice in which both PKD alleles are disrupted (all these homozygous animals die in utero). By contrast, heterozygous PKD KO mice develop only a few cysts by adulthood. These observations were reconciled by the demonstration that 'two hits' are required for development of the cystic phenotype [16] - the first being the germline mutation, followed by a somatic mutation in the remaining allele. Since the second hit would be predicted to be a rare and stochastic event, affected cells would probably be few and far between and cysts would be borne from individual cells rather than epithelial fields. Consistent with this scheme, epithelial cells harvested from at least some cysts were shown to be monoclonal [16]. However, more recent studies in chimeric mice suggest that part of the cyst wall can be formed by epithelial cells retaining the heterozygous state, raising the possibility that environmental cues elaborated by one group of cells may influence the phenotype of neighboring cells in the nephron [17]. The trans-heterozygous state (loss of one PKD1 allele and one PKD2 allele) represents another variation on the two-hit paradigm but is generally insufficient for cyst formation. However, there is evidence that the disease arising from homozygous loss of one PKD gene (due to the germline mutation compounded by somatic loss of the remaining allele) becomes more severe in the context of a co-existent germline deletion of one allele of the other PKD gene in a trans-heterozygous murine model [18]. Finally, a recent murine hypomorphic PKD1 model indicates that there might be a threshold level of pc-1 expression below which the polycystic phenotype develops, without the need for complete loss of functional protein [19].

\section{The Two Polycystins Function in the Same Pathway}

The similarity of the two ADPKD phenotypes and the molecular interactions between the two polycystins strongly suggest that the two proteins function in the same disease-related pathway. The first direct genetic evidence for this was derived from experiments in Caenorhabditis elegans, where loss of the worm pc-1-homologue lov-1 resulted in a disturbance of mating behavior that was exactly replicated by loss of the worm pc-2 [20]. In the worm, both proteins are expressed in the cilia of sensory neurons. On the other hand, the functions of $\mathrm{pc}-1$ and -2 are not so neatly superimposed in mice. Although pc-1 $\mathrm{KO}$ in mice gives rise to renal and pancreatic cysts just as seen in pc-2 KO mice, the two murine models differ in important ways. Polycystin-2 KO results in randomization of the left-right axis, perhaps due to loss of the capacity of embryonic nodal cilia to detect the flow of fluid that establishes lateralization. By contrast, left-right randomization is not seen in pc-1 KO mice. Conversely, pc-1 KO mice exhibit skeletal abnormalities that have not been described in pc-2 KO animals. Along these lines, pc- 1 and pc-2 expression at the tissue level is not always concor- 


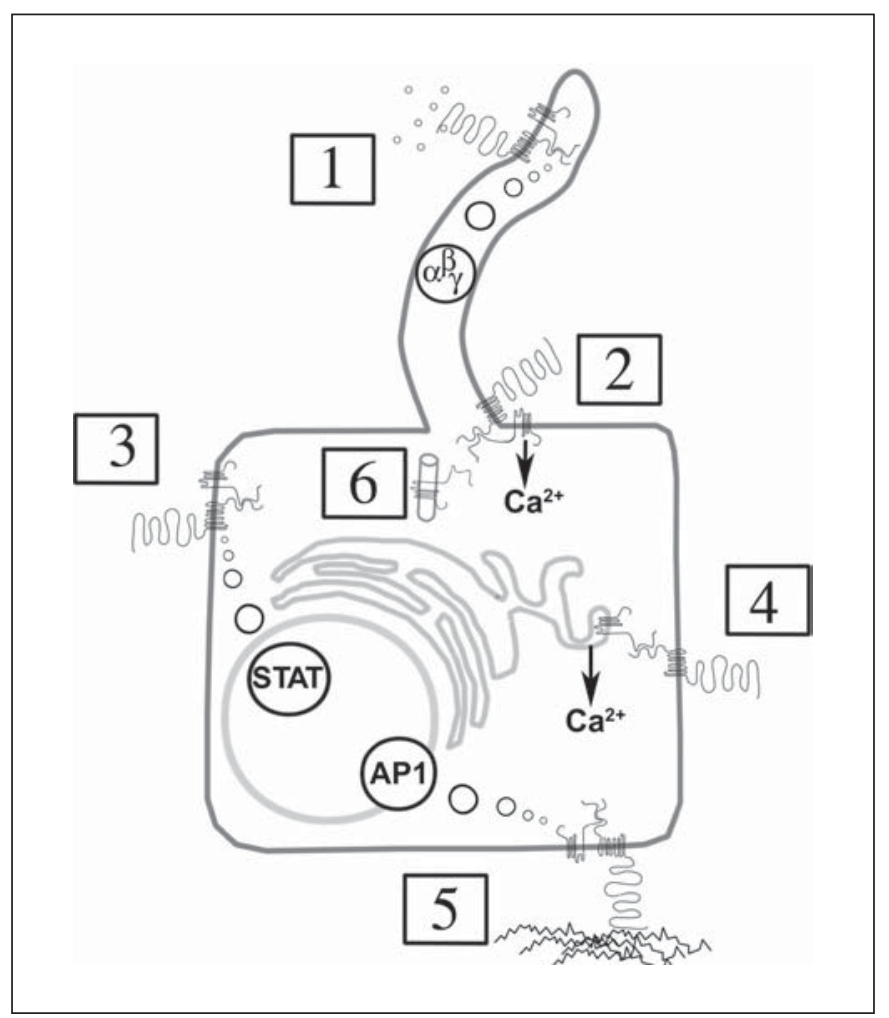

Fig. 2. The polycystin complex probably responds to one or more extracellular signals by activating multiple intracellular signal transduction cascades. pc- 1 and pc- 2 have been shown to modulate a number of discrete signal transduction cascades including activation of the JAK/STAT pathway (Janus kinase/signal transducers and activators of transcription), AP-1 (a dimeric transcription factor composed of jun and one of a range of other subunits) and heterotrimeric $\mathrm{G}$ proteins. The polycystin complex might be responsive to soluble ligands (1), cell-cell contact (3) or cell-matrix interactions (5). The polycystins also signal through changes in cytoplasmic $\mathrm{Ca}^{2+}$. Cilial deflection results in $\mathrm{Ca}^{2+}$ entry and subsequent $\mathrm{Ca}^{2+}$-mediated $\mathrm{Ca}^{2+}$ release from the endoplasmic reticulum (ER) (2). The polycystin complex is also involved in $\mathrm{ER} \mathrm{Ca}^{2+}$ turnover (4). Even if non-cilial pc-2 were to be restricted to the ER membrane, interactions between the polycystins might still be possible since the ER is a highly dynamic structure that could migrate into proximity with the plasma membrane. In addition to the sites listed above, pc-2 has also been localized to the basal body (6), a centriole-derived structure implicated in both ciliagenesis and, as the centrosome, the arrangement of the mitotic spindle.

dant in time or space. Although some subcellular expression patterns overlap (mutual localization to the apical cilia) some investigators hold the view that $\mathrm{pc}-2$ is confined to the cilia and ER and is not represented at the other plasma membrane locations ascribed to pc-1. However, even if pc-2 is not distributed to all the plasma membrane domains inhabited by pc-1, the mobility of the ER might still permit molecular interactions between the two proteins. Nonetheless, in addition to their concordant functions, the polycystins probably also function independently of each other in discrete pathways that might have nothing to do with ADPKD.

\section{What Are the Functions of the Polycystins That Are Relevant to ADPKD? (fig. 2)}

ADPKD cyst epithelial cells are flattened, lose tubulespecific markers and express a number of proteins associated with proliferation; all indicators of de-differentiation from the stable tubule epithelial phenotype [21]. These observations suggest that the polycystins might serve to maintain terminal differentiation in the renal tubular epithelium. The molecular characteristics and localization of the polycystins strongly suggest a role for the polycystin complex as a transducer of extracellular stimuli. Therefore it is likely that the fundamental defect in ADPKD is a profound disturbance of cellular responses to environmental cues, which leads to de-differentiation of renal tubular epithelia.

\section{Polycystins and Cilia}

In the same year that the worm polycystin homologues were identified as a functional complex residing in the cilia of sensory neurons, further examination of an established mouse model for PKD revealed that the protein product of the gene linked to the cystic phenotype, polaris, localized to the cilia and was required for the normal assembly of this organelle [22]. Since then, detailed examination of a number of other established murine models for PKD has revealed that most (but not all) arise from mutations in genes encoding cilia-associated proteins. Indeed, the autosomal recessive form of human polycystic kidney disease (ARPKD) is caused by loss of function of the PKHD1 gene product (a protein called fibrocystin or polyductin), which also localizes to the central cilia of renal and other epithelia [23]. Although the function of the central cilium of renal epithelial cells remains a mystery, both pc- 1 and pc-2 appear to be required for the cell calcium response to flow across the apical membrane of ciliated cells, a response thought to be mediated by cilial deflection [24]. Since pc-2 belongs to the TRP family, which includes mechanosensors, the pc- $1 / \mathrm{pc}-2$ complex might detect deformation of the cilial membrane and mediate calcium influx with resultant calcium-mediated calcium release from the ER. However, regarding the cilia as solely a flow sensor is probably an oversimplification. 
The Chlamydomonas flagellum (a cilium) contains well over 500 proteins indicating that cilia are actually rather complex organelles [25]. Cilia might be crucial regulators of cellular differentiation through a role in signal transduction, as chemosensors or as regulators of the cell cycle. The cilial role of the polycystins, and how cilia relate to the ADPKD pathway, will likely remain uncertain until we more fully understand the broader cell biology of cilia and are able to develop more physiological functional readouts.

Although attractive, the hypothesis that it is loss of the cilial responsiveness to luminal flow that serves as the trigger for the chain of events leading to cyst formation remains unproven. Cystogenesis could just as easily be initiated by cellular de-differentiation arising from disturbances in a wide range of alternative pathways. In addition, given the widespread subcellular distribution of the polycystins, these alternative pathways might be related to the cilia, or arise in other cellular compartments. Even if cilia are dysfunctional in ADPKD, the cilial abnormality might be an indicator of a more central cell biological abnormality that is the actual driving mechanism for the disease process. This possibility is suggested by the fact that one organelle, the centriole, is dually responsible for the organization of cilia (basal body) and mitotic spindles (centrosome). Since pc-2 localizes to the basal body, polycystin signaling might be implicated in both the organization of mitosis and cilia function, with the former being in the disease-specific pathway. Indeed, it has recently been demonstrated that the normally longitudinal axis of mitosis in the developing nephron becomes disorganized in two animal models for cystic disease, the Pck rat and HNF1 $\beta$ kidney-specific KO mouse [M. Pontoglio, pers. commun.].

\section{Polycystins and Other Pathways}

The polycystins have been identified in a number of non-cilial locations, and implicated in a variety of signal transduction pathways not (yet) associated with cilial function. Perturbation of any one of these pathways could lead to the kind of profound alterations in cellular differentiation and proliferation that might culminate in cyst formation. Many of these pathways also appear to require interactions between $\mathrm{pc}-1$ and $\mathrm{pc}-2$, which would substantiate their relevance to the ADPKD phenotype. As depicted in figure 1, pc-1 has an $\mathrm{NH}_{2}$ terminal domain that looks like a receptor and has been shown to interact with matrix proteins and carbohydrates. Perhaps the cilial localization of the polycystins serves to ensure that pc-1 (and likely many other cell surface receptors [26]) gains access to extracellular ligands, unimpeded by the unstirred layer immediately adjacent to the external leaflet of the cell membrane. Hence, loss of cilial integrity from any number of divergent genetic defects might not only interfere with flow sensing, but also lead to displacement of the components of other signal transduction cascades required for maintenance of cellular differentiation.

\section{Polycystins and $\mathrm{Ca}^{2+}$ Signaling}

The physical interaction between pc- 1 and $\mathrm{pc}-2$ raises the possibility that the binding of pc-1 to some extracellular ligand leads to modulation of the channel function of pc-2, a situation curiously analogous to the sea urchin fertilization response. The idea that $\mathrm{pc}-2$ is a membrane channel regulated by pc-1 is supported by the observations that pc-2 can function as a plasma membrane calcium channel that requires pc- 1 for stabilization at the cell surface in intact cells [12] and that the isolated $\mathrm{COOH}$ terminus of pc- 1 attenuates $\mathrm{pc}-2$ channel rundown in lipid bilayer experiments [27]. Even if pc-2 is indeed confined to the ER, interaction with plasma membrane pc-1 might still be permitted by way of apposition of the two membrane systems, depending upon the configuration of the cytoskeleton. In this way the polycystin complex might regulate calcium turnover across the ER membrane. Since pc-1 does not appear to be a channel [28], it is quite likely that the effects of pc-1 on the regulation of intracellular calcium seen in numerous studies are actually mediated by interactions with pc-2, and therefore fulfill the 'common pathway' condition to be considered as relevant to ADPKD pathogenesis. Loss of functional pc-1 prolongs ligand-activated cell calcium responses [24]. Conversely, heterologous expression of pc-1 appears to abbreviate the cell calcium response through acceleration of ER calcium re-uptake [29], perhaps through modulation of the function of ER localized pc-2. Several studies have shown that the isolated cytoplasmic $\mathrm{COOH}$ terminal of pc-1 also influences cellular calcium responses. In one study, the pc-1 truncation prolonged ligand-activated cell calcium responses [30] and in another, caused proliferation in association with subtle elevation of basal cell calcium concentration and activation of PKC [31]. Along these lines, others have reported that the pc-1 truncation activates NFAT (nuclear factor of activated T cells) signaling through increased cell calcium [32]. A similar truncated pc-1 construct transformed the cAMP 
growth phenotype of renal tubular cells from suppression (normal) to proliferation (as seen in cystic epithelia); an effect replicated by maneuvers that lowered cytoplasmic calcium concentration [33, 34]. It should be noted that the cytoplasmic $\mathrm{COOH}$ terminal of $\mathrm{pc}-1$ has the potential to act as a dominant negative with respect to native fulllength protein [M. Sutters, unpubl. observations], so studies utilizing the truncation might in fact be evoking a 'polycystic' phenotype.

\section{Other Signal Transduction Pathways Modulated by the Polycystin Complex}

Interactions between the two polycystins are required for their participation in a number of other pathways with the potential to influence cellular differentiation. The effect of pc-2 to activate the transcription factor AP-1 is augmented by pc-1 [35]. Polycystin-1 activation of the JAK/STAT pathway (which inhibits proliferation through increased expression of p21) depends upon interaction with pc-2 [36]. Polycystin-1 has the potential to activate $\mathrm{G} \alpha_{\mathrm{i}}$ type heterotrimeric $\mathrm{G}$ proteins, an effect that is antagonized by co-expressed pc-2 [37].

\section{Conclusion}

Evidence is accumulating to suggest that ADPKD is the consequence of cellular de-differentiation stemming from the loss of a cell's capacity to recognize and correctly integrate signals arising in the extracellular environment. The external signals may be matrix proteins, soluble ligands or mechanical stimuli generated between cells, or arise as a consequence of deformation of the central apical cilia. Although the polycystins regulate a number of signal transduction pathways with the potential to influence cellular differentiation, much of the direct and circumstantial evidence indicates that the disease phenotype is triggered by dysregulation of intracellular calcium responses.

\section{Acknowledgements}

M. Sutters is supported by the NIH (KO8 DK066323-01), the Polycystic Kidney Disease Foundation and the National Kidney Foundation of Maryland.

\section{References}

1 The European Polycystic Kidney Disease Consortium: The polycystic kidney disease 1 gene encodes a $14 \mathrm{~kb}$ transcript and lies within a duplicated region on chromosome 16. Cell 1994:77:881-894.

-2 Mochizuki T, Wu G, Hayashi T, Xenophontos S, Veldhuisen B, Saris JJ, Reynolds DM, Cai Y, Gabow PA, Pierides A, Kimberling WJ, Breuning MH, Deltas CC, Peters DJ, Somlo S: $\mathrm{PKD} 2$, a gene for polycystic kidney disease that encodes an integral membrane protein. Science 1996;272:1339-1342.

3 Pei Y, Paterson AD, Wang KR, He N, Hefferton D, Watnick T, Germino GG, Parfrey P, Somlo S, St George-Hyslop P: Bilineal disease and trans-heterozygotes in autosomal dominant polycystic kidney disease. Am J Hum Genet 68:355-363.

4 Moy G, Mendoza L, Schulz J, Swanson W, Glabe C, Vacquier V: The sea urchin sperm receptor for egg jelly is a modular protein with extensive homology to the human polycystic kidney disease protein, PKD1. J Cell Biol 1996;133:809-817.

-5 Qian F, Boletta A, Bhunia AK, Xu H, Liu L, Ahrabi AK, Watnick TJ, Zhou F, Germino GG: Cleavage of polycystin-1 requires the receptor for egg jelly domain and is disrupted by human autosomal-dominant polycystic kidney disease 1-associated mutations. Proc Natl Acad Sci USA 2002;99:16981-16986.
-6 Parnell SC, Magenheimer BS, Maser RL, Rankin CA, Smine A, Okamoto T, Calvet JP: The polycystic kidney disease-1 protein, polycystin-1, binds and activates heterotrimeric Gproteins in vitro. Biochem Biophys Res Commun 1998;251:625-631.

-7 Qian F, Germino FJ, Cai Y, Zhang X, Somlo S, Germino GG: PKD1 interacts with PKD2 through a probable coiled-coil domain. Nat Genet 1997;16:179-183.

8 Huang CL: The transient receptor potential superfamily of ion channels. J Am Soc Nephrol 2004; 15:1690-1699.

\9 Gonzalez-Perrett S, Kim K, Ibarra C, Damiano AE, Zotta E, Batelli M, Harris PC, Reisin IL, Arnaout MA, Cantiello HF: Polycystin-2, the protein mutated in autosomal dominant polycystic kidney disease, is a $\mathrm{Ca}^{2+}$-permeable nonselective cation channel. Proc Natl Acad Sci USA 2001;98:1182-1187.

10 Koulen P, Cai Y, Geng L, Maeda Y, Nishimura S, Witzgall R, Ehrlich BE, Somlo S: Polycystin-2 is an intracellular calcium release channel. Nat Cell Biol 2002;3:191-197.

11 Yoder BK, Hou X, Guay-Woodford LM: The polycystic kidney disease proteins, polycystin1 , polycystin-2, polaris, and cystin, are co-localized in renal cilia. J Am Soc Nephrol 2002; 13:2508-2516.
12 Hanaoka K, Qian F, Boletta A, Bhunia AK, Piontek K, Tsiokas L, Sukhatme VP, Guggino WB, Germino GG: Co-assembly of polycystin1 and -2 produces unique cation-permeable currents. Nature 2000;408:990-994.

13 Jurczyk A, Gromley A, Redick S, Agustin JS, Witman G, Pazour GJ, Peters DJM, Doxsey S: Pericentrin forms a complex with intraflagellar transport proteins and polycystin-2 and is required for primary cilia assembly. J Cell Biol 2004; 166:637-643.

-14 Grimm DH, Cai Y, Chauvet V, Rajendran V, Zeltner R, Geng L, Avner ED, Sweeney W, Somlo S, Caplan MJ: Polycystin-1 distribution is modulated by polycystin- 2 expression in mammalian cells. J Biol Chem 2003;278: 36786-36793.

15 Kottgen M, Benzing T, Simmen T, Tauber R, Buchholz B, Feliciangeli S, Huber TB, Schermer B, Kramer-Zucker A, Hopker K, Simmen KC, Tschucke CC, Sandford R, Kim E, Thomas G, Walz G: Trafficking of TRPP2 by PACS proteins represents a novel mechanism of ion channel regulation. EMBO J 2005;24:705716.

16 Qian F, Watnick T, Onuchic LF, Germino GG: The molecular basis of focal cyst formation in human autosomal dominant polycystic kidney disease type I. Cell 1996;87:979-987. 
-17 Nishio S, Hatano M, Nagata M, Horie S, Koike T, Tokuhisa T, Mochizuki T: Pkd1 regulates immortalized proliferation of renal tubular epithelial cells through p53 induction and JNK activation. J Clin Invest 2005;115:910-918.

- 18 Wu G, Tian X, Nishimura S, Markowitz GS, D’Agati V, Hoon Park J, Yao L, Li L, Geng L, Zhao H, Edelmann W, Somlo S: Trans-heterozygous Pkd1 and Pkd2 mutations modify expression of polycystic kidney disease. Hum Mol Genet 2002;11:1845-1854.

19 Lantinga-van Leeuwen IS, Dauwerse JG, Baelde HJ, Leonhard WN, van de Wal A, Ward CJ, Verbeek S, DeRuiter MC, Breuning MH, de Heer E, Peters DJM: Lowering of Pkd1 expression is sufficient to cause polycystic kidney disease. Hum Mol Genet 2004;13:3069-3077.

-20 Barr MM, DeModena J, Braun D, Nguyen CQ, Hall DH, Sternberg PW: The Caenorhabditis elegans autosomal dominant polycystic kidney disease gene homologs lov-1 and pkd-2 act in the same pathway. Curr Biol 2001;11:13411346.

21 Calvet JP: Polycystic kidney disease: primary extracellular matrix abnormality or defective cellular differentiation? Kidney Int 1993;43: 101-108.

-22 Taulman PD, Haycraft CJ, Balkovetz DF, Yoder BK: Polaris, a protein involved in left-right axis patterning, localizes to basal bodies and cilia. Mol Biol Cell 2001;12:589-599.

-23 Ward CJ, Yuan D, Masyuk TV, Wang X, Punyashthiti R, Whelan S, Bacallao R, Torra R, LaRusso NF, Torres VE, Harris PC: Cellular and subcellular localization of the ARPKD protein; fibrocystin is expressed on primary cilia. Hum Mol Genet 2003;12:2703-2710.
24 Nauli S, Alenghat F, Luo Y, Williams E, Vassilev P, Li X, Elia A, Lu W, Brown E, Quinn S, Ingber D, Zhou J: Polycystins 1 and 2 mediate mechanosensation in the primary cilium of kidney cells. Nat Genet 2003;33:129-137.

25 Pazour GJ, Agrin N, Leszyk J, Witman GB: Proteomic analysis of a eukaryotic cilium. J Cell Biol 2005; 170:103-113.

26 Huangfu D, Anderson KV: From the cover: cilia and hedgehog responsiveness in the mouse. Proc Natl Acad Sci USA 2005;102: 11325-11330.

27 Xu GM, Gonzalez-Perrett S, Essafi M, Timpanaro GA, Montalbetti N, Arnaout MA, Cantiello HF: Polycystin-1 activates and stabilizes the polycystin-2 channel. J Biol Chem 2003; 278:1457-1462.

28 Delmas P, Padilla F, Osorio N, Coste B, Raoux M, Crest M: Polycystins, calcium signaling, and human diseases. Biochem Biophys Res Commun 2004;322:1374-1383.

$>29$ Hooper K, Boletta A, Germino G, Hu Q, Ziegelstein R, Sutters M: Expression of polycystin1 enhances endoplasmic reticulum calcium uptake and decreases capacitative calcium entry in ATP-stimulated MDCK cells. Am J Physiol Renal Physiol 2005;289:F521-F530.

30 Wildman SS, Hooper KM, Turner CM, Sham JSK, Lakatta EG, King BF, Unwin RJ, Sutters M: The isolated polycystin-1 cytoplasmic $\mathrm{COOH}$ terminus prolongs ATP-stimulated $\mathrm{Cl}$ conductance through increased $\mathrm{Ca}^{2+}$ entry. Am J Physiol Renal Physiol 2003;285:F1168F1178.

31 Manzati E, Aguiari G, Banzi M, Manzati M, Selvatici R, Falzarano S, Maestri I, Pinton P, Rizzuto R, del Senno L: The cytoplasmic Cterminus of polycystin-1 increases cell proliferation in kidney epithelial cells through serum-activated and $\mathrm{Ca}^{2+}$-dependent pathway(s). Exp Cell Res 2005;304:391-406.
32 Puri S, Magenheimer BS, Maser RL, Ryan EM, Zien CA, Walker DD, Wallace DP, Hempson SJ, Calvet JP: Polycystin-1 activates the calcineurin/NFAT (nuclear factor of activated Tcells) signaling pathway. J Biol Chem 2004; 279:55455-55464.

>33 Sutters M, Yamaguchi T, Maser RL, Magenheimer BS, St. John PL, Abrahamson DR, Grantham JJ, Calvet JP: Polycystin-1 transforms the cAMP growth-responsive phenotype of M-1 cells. Kidney Int 2001;60:484-494.

34 Yamaguchi T, Wallace DP, Magenheimer BS, Hempson SJ, Grantham JJ, Calvet JP: Calcium restriction allows cAMP activation of the B-Raf/ERK pathway, switching cells to a cAMP-dependent growth-stimulated phenotype. J Biol Chem 2004;279:40419-40430.

35 Arnould T, Sellin L, Benzing T, Tsiokas L, Cohen HT, Kim E, Walz G: Cellular activation triggered by the autosomal dominant polycystic kidney disease gene product PKD2. Mol Cell Biol 1999; 19:3423-3434.

-36 Bhunia AK, Piontek K, Boletta A, Liu L, Qian F, Xu PN, Germino FJ, Germino GG: PKD1 induces p2 1 (WAF1) and regulation of the cell cycle via direct activation of the JAK-STAT signaling pathway in a process requiring PKD2. Cell 2002;109:157-168.

37 Delmas P, Nauli SM, Li X, Coste B, Osorio N, Crest M, Brown DA, Zhou J: Gating of the polycystin ion channel signaling complex in neurons and kidney cells. FASEB J 2004; 18 : 740-742. 